\section{(2) OPEN ACCESS}

\begin{abstract}
- Additional material is
published online only. To view please visit the journal online (http://dx.doi.org/10.1136/ heartjnl-2019-315499).
\end{abstract}

${ }^{1}$ Department of Clinical Sciences and Nutrition, University of Chester, Chester, UK 'BACPR Diet Working Group ${ }^{3}$ Connolly Hospital Blanchardstown, Dublin, Ireland ${ }^{4}$ Imperial College Healthcare NHS Trust, St Mary's Hospital, London, UK

'Whittington Health NHS Trust, London, UK

${ }^{6}$ Doddington Hospital - Cambridgeshire and Peterborough NHS Foundation Trust, Doddington, UK ${ }^{7}$ Salford Royal NHS Foundation Trust, Salford, UK

${ }^{8}$ Department of Community Cardiology, Central London Community NHS Trust, Berkhamstead, UK

${ }^{9}$ Norfolk and Norwich University Hospital, Norwich, UK

\section{Correspondence to}

Dr Tom Butler, Clinical Sciences and Nutrition, University of Chester, Chester CH1 4BJ, UK; t.butler@chester.ac.uk

Received 5 November 2019 Revised 28 December 2019 Accepted 2 January 2020 Published Online First 25 February 2020

\section{Check for updates}

(C) Author(s) (or their employer(s)) 2020. Re-use permitted under CC BY-NC. No commercial re-use. See rights and permissions. Published by BMJ.

To cite: Butler T, Kerley CP, Altieri $N$, et al. Heart

2020;106:724-731.

\title{
Optimum nutritional strategies for cardiovascular disease prevention and rehabilitation (BACPR)
}

\author{
Tom Butler (10 ${ }^{1,2}$ Conor P Kerley, ${ }^{2,3}$ Nunzia Altieri, ${ }^{2,4}$ Joe Alvarez, ${ }^{2,5}$ Jane Green, ${ }^{2,6}$ \\ Julie Hinchliffe, ${ }^{2,7}$ Dell Stanford, ${ }^{2,8}$ Katherine Paterson ${ }^{2,9}$
}

\section{ABSTRACT}

Nutrition has a central role in both primary and secondary prevention of cardiovascular disease yet only relatively recently has food been regarded as a treatment, rather than as an adjunct to established medical and pharmacotherapy. As a field of research, nutrition science is constantly evolving making it difficult for patients and practitioners to ascertain best practice. This is compounded further by the inherent difficulties in performing double-blind randomised controlled trials. This paper covers dietary patterns that are associated with improved cardiovascular outcomes, including the Mediterranean Diet but also low-carbohydrate diets and the potential issues encountered with their implementation. We suggest there must be a refocus away from macronutrients and consideration of whole foods when advising individuals. This approach is fundamental to practice, as clinical guidelines have focused on macronutrients without necessarily considering their source, and ultimately people consume foods containing multiple nutrients. The inclusion of food-based recommendations aids the practitioner to help the patient make genuine and meaningful changes in their diet. We advocate that the cardioprotective diet constructed around the traditional Mediterranean eating pattern (based around vegetables and fruits, nuts, legumes, and unrefined cereals, with modest amounts of fish and shellfish, and fermented dairy products) is still important. However, there are other approaches that can be tried, including low-carbohydrate diets. We encourage practitioners to adopt a flexible dietary approach, being mindful of patient preferences and other comorbidities that may necessitate deviations away from established advice, and advocate for more dietitians in this field to guide the multi-professional team.

\section{INTRODUCTION}

There are multiple modifiable risk factors for cardiovascular disease (CVD), many of which are modifiable via changes in diet and physical activity. This combination is widely recognised in clinical guidelines as being important in both primary and secondary prevention, ${ }^{1-3}$ and nutritional education is an important element of cardiac rehabilitation (CR). However, the area of nutrition is frequently over complicated with conflicting information. Such an example is salt, with recent evidence suggesting the benefit of salt restriction is greatest in those already with hypertension (HTN), ${ }^{4}$ and that both low and high intake may be associated with increased mortality. ${ }^{5}$
Patients with cardiac disease are becoming increasingly more complex due to the number of comorbidities present. Data from the National Audit of Cardiac Rehabilitation (NACR) show HTN to be the most common comorbidity (49.9\%), followed by hypercholesterolaemia/dyslipidaemia $(31.7 \%)$ and then diabetes $(24.5 \%) .^{6}$ Poor diet is a significant modifiable risk factor in these comorbidities, and all outcomes reported by the NACR could likely be improved with increased emphasis on addressing lifestyle (nutrition and exercise).

The Diet working group was established by British Association for Cardiovascular Prevention and Rehabilitation (BACPR) and was actioned to provide a guide through current controversies in cardiovascular nutrition, in addition to signposting researchers to current gaps in evidence. The group sought views from professionals working in the area of CR and aims to provide specific recommendations to answer the many common questions encountered by healthcare professionals working in this field. This paper reviews both macronutrients and the key food groups healthcare professionals sought clarity on.

The objectives of this paper are to review the area of cardiovascular nutrition and provide recommendations for practitioners to help patients make healthy eating decisions. We also aim to identify current gaps in evidence and suggestions for future research.

\section{MACRONUTRIENTS \\ Protein}

Summary messages regarding dietary protein are presented in table 1 . Detailed study ${ }^{7-13}$ analysis examining protein intake and CVD are presented in online supplementary table 1 .

There is a long-standing argument that high protein intakes lead to renal failure with a recent observational study suggesting that increased protein intake post-myocardial infarction (MI) was associated with a greater decline in renal function ${ }^{7}$ and increased risk of mortality. ${ }^{8}$ Of interest, dairy or plant protein sources showed a much weaker association when compared with animal protein, and the relationship between protein and outcome variables was stronger in those with predisposing disease, for example, diabetes. This indicates that the source of dietary protein may be important to consider. Indeed, randomised controlled trials show that the quality of meat (in addition to the whole diet) is likely to be an important factor to consider 
Table 1 Protein

\begin{tabular}{|c|c|c|}
\hline Macronutrient & Source and quality & Summary \\
\hline Protein & $\begin{array}{l}\text { Animal and plant } \\
\text { Lean animal protein (defined by } 0^{\prime} \text { Connor et } \mathrm{al}^{9} \text { ) as }<10 \mathrm{~g} \text { total fat, }<5 \mathrm{~g} \\
\text { saturated fat and }<95 \mathrm{mg} \text { cholesterol } / 100 \mathrm{~g} \text { ) is a better choice than fattier } \\
\text { types } \\
\text { Sources of animal protein include fish, poultry, meat, eggs and dairy. } \\
\text { Processed meat is also included in this category as a source of protein } \\
\text { Sources of plant protein include nuts and seeds (almonds, walnuts, } \\
\text { cashews), pulses (including chickpeas, lentils, bean) } \\
\text { Animal proteins are complete (contain the nine essential amino acids) } \\
\text { whereas plant proteins do not. This has often led to plant protein being } \\
\text { described as low quality }\end{array}$ & 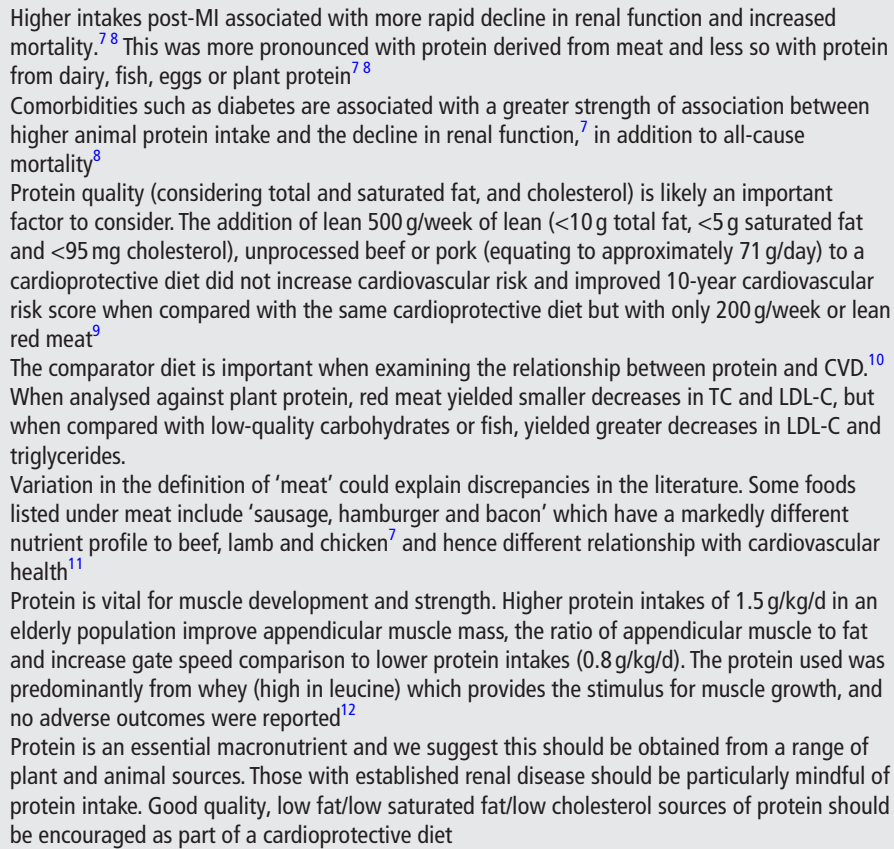 \\
\hline
\end{tabular}

CVD, cardiovascular disease; LDL-C, low-density lipoproten-cholesterol; MI, myocardial infarction; TC, total cholesterol.

in explaining this relationship, with evidence suggesting that the addition of lean red meat to an already low saturated fat cardioprotective diet does not impact negatively on blood lipids. ${ }^{9}$ The saturated fat content of the comparison $\operatorname{diet}^{10}$ may be an additional piece of the puzzle in explaining the impact dietary protein (and its source) has on cardiovascular health. ${ }^{11}$

Protein provides the main components for muscle synthesis and consensus opinion suggests that protein intakes should be higher in the elderly ${ }^{12}$ with intakes up to $1.5 \mathrm{~g} / \mathrm{kg} / \mathrm{d}$ being shown to improve body composition in an elderly, frail population. ${ }^{13}$ Collectively, these studies highlight an important role for protein in cardiovascular health, especially when considering (a) source (animal vs plant); (b) quality and (c) overall diet quality.

\section{CARBOHYDRATES}

Summary messages regarding dietary carbohydrate are presented in table 2. Detailed study ${ }^{14-19}$ analysis examining carbohydrate intake and CVD are presented in online supplementary table 1.

The Prospective Urban Rural Epidemiology study raised carbohydrates to the forefront of cardiovascular health with headline data showing higher carbohydrate intake was

Table 2 Carbohydrate

\begin{tabular}{ll}
\hline Macronutrient & Source and quality \\
\hline Carbohydrates & Plant \\
& Refined and whole grain breads and cereals, pastas, rice, fruits and \\
& vegetables, and cakes, biscuits and sugar-sweetened beverages \\
& Carbohydrate sources that are based around refined white flour should \\
& be reduced/avoided and replaced with better quality sources (such as \\
& whole grain cereals and breads, or fruits and vegetables). \\
& Education may be required to explain to individuals that carbohydrates \\
& are not only found in breads, cereals and pastas but are also present in \\
& numerous vegetables and fruits
\end{tabular}

\section{Summary}

Sources of carbohydrate are important to the relationship of carbohydrates with cardiovascular health. Data from the PURE study indicated higher carbohydrate intake was associated with increased mortality although the sources and quality of carbohydrate was poor, likely explaining this relationship. ${ }^{14}$ Additionally, the high percentage energy from carbohydrate likely displaced other beneficial nutrients (protein and fat) from the diet.

There appear to be different associations between low-carbohydrate high animal fat and protein diets versus low-carbohydrate high plant fat and protein diets and mortality. A low-carbohydrate diet high in plant fat and protein was not associated with increased mortality, whereas a low-carbohydrate diet high animal fat and protein diet was. ${ }^{15} 16$

Higher fibre intake is inversely associated with cardiovascular and all-cause mortality post-MI. ${ }^{17}$

Prospective studies support a role for whole grains in cardiovascular health, with whole grain bread, pasta, cereals and oatmeal associated with reduced all-cause mortality, with similar observations for cardiovascular mortality. ${ }^{118}$ However, randomised controlled trials do not support a role for specifically increasing whole grain consumption to reduce lipids, blood pressure and body mass index. ${ }^{19}$ We recommend that patients are encouraged to consume good quality sources of carbohydrate, such as vegetables and whole grain cereals that are high in fibre as part of a cardioprotective diet. Reducing dietary carbohydrate may be advantageous to those with altered blood glucose control 


\begin{tabular}{|c|c|c|}
\hline Macronutrient & Source and quality & Summary \\
\hline Fats & $\begin{array}{l}\text { Animal and plant } \\
\text { Sources of animal fat include fish, poultry, meat and dairy } \\
\text { (including butter, cream and cheese). Eggs are not listed } \\
\text { here due to their low fat content. The fatty acid profile can } \\
\text { be affected by what the animal has been fed. Grass fed beef } \\
\text { tends to have a lower total fat content than grain-fed beef. } \\
\text { Fatty fish (mackerel, salmon, sardines, herring and trout } \\
\text { contain the n3 polyunsaturated fats eicosapentaenoic acid } \\
\text { and docosahexaenoic acid). Meat can also vary substantially } \\
\text { regarding total and saturated fat content. } \\
\text { Sources of plant fat include nuts and seeds, and vegetables } \\
\text { (including oils). The fatty acid profile of oils varies hugely. } \\
\text { Oils high in n6 polyunsaturated fats include soybean, } \\
\text { sunflower, safflower and walnut. Oils that contain more n3 } \\
\text { polyunsaturated fats include flaxseed, walnut and rapeseed. } \\
\text { Olive oil contains predominantly n9 monounsaturated fats. } \\
\text { Coconut oil (a plant-based oil) contains predominantly saturated } \\
\text { fat. }\end{array}$ & 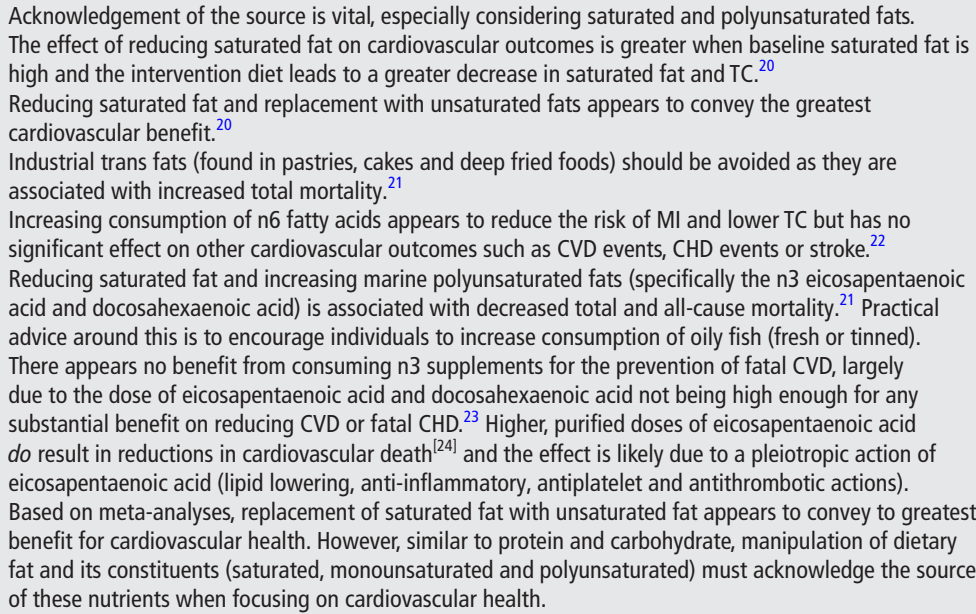 \\
\hline
\end{tabular}

$\mathrm{CHD}$, coronary heart disease ; $\mathrm{CVD}$, cardiovascular disease; $\mathrm{Ml}$, myocardial infarction; $\mathrm{TC}$, total cholesterol.

associated with increased all-cause and cardiovascular (CV) mortality. ${ }^{14}$ However, recent meta-analyses examining the association between carbohydrate intake and cardiovascular health have suggested a U-shaped relationship between carbohydrate and all-cause mortality, specifically in those consuming a lowcarbohydrate diet higher in animal protein and fat. ${ }^{15} 16$

Prospective cohort studies have shown fibre intake to be inversely associated with reduced cardiovascular and all-cause mortality post-MI. ${ }^{17}$ In this study, ${ }^{17}$ only cereal fibre was significantly associated with a reduction in cardiovascular and all-cause mortality in both men and women. One of the most prominent sources of cereal fibre is whole grain, and whole grain is frequently cited as being beneficial for health ${ }^{11}{ }^{18}$; however, there is disparity between meta-analyses of cohort studies and results from randomised controlled trials. ${ }^{19}$ Such discrepancy between this and prospective studies likely highlights the importance of adequately defining whole grain, and taking a whole diet approach when considering cardioprotective foods.

\section{FATS}

Summary messages regarding dietary fat are presented in table 3 . Detailed study ${ }^{20-24}$ analysis examining fat intake and CVD are presented in online supplementary table 1.

The correct balance of dietary fats is a key to cardiovascular health; however, as with carbohydrates and protein types, sources and amounts have made determining effects difficult. Saturated fat has long been suggested to be harmful for cardiovascular health; however, a recent meta-analysis ${ }^{20}$ suggested that reducing saturated fat did not seem to effect total mortality or CVD mortality. However, a reduction in combined cardiovascular events of $17 \%$ was shown with a reduction in saturated fat. Greater decreases in events were seen for studies that replaced saturated fat with polyunsatured fats when compared with monounsaturated fats, carbohydrate or protein. ${ }^{20}$ Thus, it would appear reducing saturated fat and replacement with unsaturated fat conveys the greatest cardiovascular benefit, not necessarily reducing saturated fat and replacing with refined carbohydrate, and some of this effect may be modified by where the saturated fat is found that is, dairy versus processed baked goods.

Increased trans fat intake is positively associated with total mortality, along with animal monounsaturated fats, alpha linolenic acid and arachidonic acid. ${ }^{21}$ In this same study, marine n3 polyunsaturated fat and replacement of saturated fat with plant monounsaturated fat were associated with lower total and CVD mortality. This latter study acknowledges the subtypes of fat such as n3 (alpha linolenic acid, eicosapentaenoic acid and docosahexaenoic acid) and $\mathrm{n} 6$ fatty acids (linoleic acid and gammalinoleic acid). Indeed, n6 fatty acids have been shown to reduce risk of MI, as well as reducing total cholesterol (TC), with these findings possibly relating to both baseline $\mathrm{n} 6$ intake and dose of n6 provided. $^{22}$ This latter point is similar to observations made in the most recent analysis of fish oil supplements and cardiovascular health. This analysis indicated no benefit from supplementation on reducing fatal coronary heart disease (CHD) or any CVD in people with or at high risk of $C V D,{ }^{23}$ primarily due to the low dose of eicosapentaenoic acid and docosahexaenoic acid used in the included studies (226 to $1800 \mathrm{mg} /$ day and 0 to $1700 \mathrm{mg} /$ day, respectively). These null results contrast substantially with the positive effects seen with the Reduction of Cardiovascular Events with Icosapent Ethyl-Intervention Trial utilising a highly purified form of eicosapentaenoic acid ( $4 \mathrm{~g} /$ day). ${ }^{24}$ Further research into specific fat replacements for saturated fat is warranted and it is unclear whether there is additional benefit to maintaining a lower saturated fat diet while on lipid-lowering treatment. As with protein and carbohydrate, the source of the nutrient (ie, food) matters.

\section{FOODS AND FOOD GROUPS}

Detailed information considering food and food groups are shown in online supplementary table 2.

\section{Fruits and vegetables}

The grouping of fruits together with vegetables is inaccurate, similarly to the grouping of red and processed meat. This ignores distinct differences between fruits and vegetables in terms of their nutrient profile, and hence their association with disease. Fruits and vegetables high in nutrients are hypothesised to be cardioprotective and have consistently been associated with reduced CVD. ${ }^{25}$ Hence, fruits and vegetables are cornerstones of cardioprotective dietary patterns (eg, dietary approaches to stop hypertension (DASH), Mediterranean) and dietary guidelines ubiquitously recommend them. ${ }^{1-3}$ 


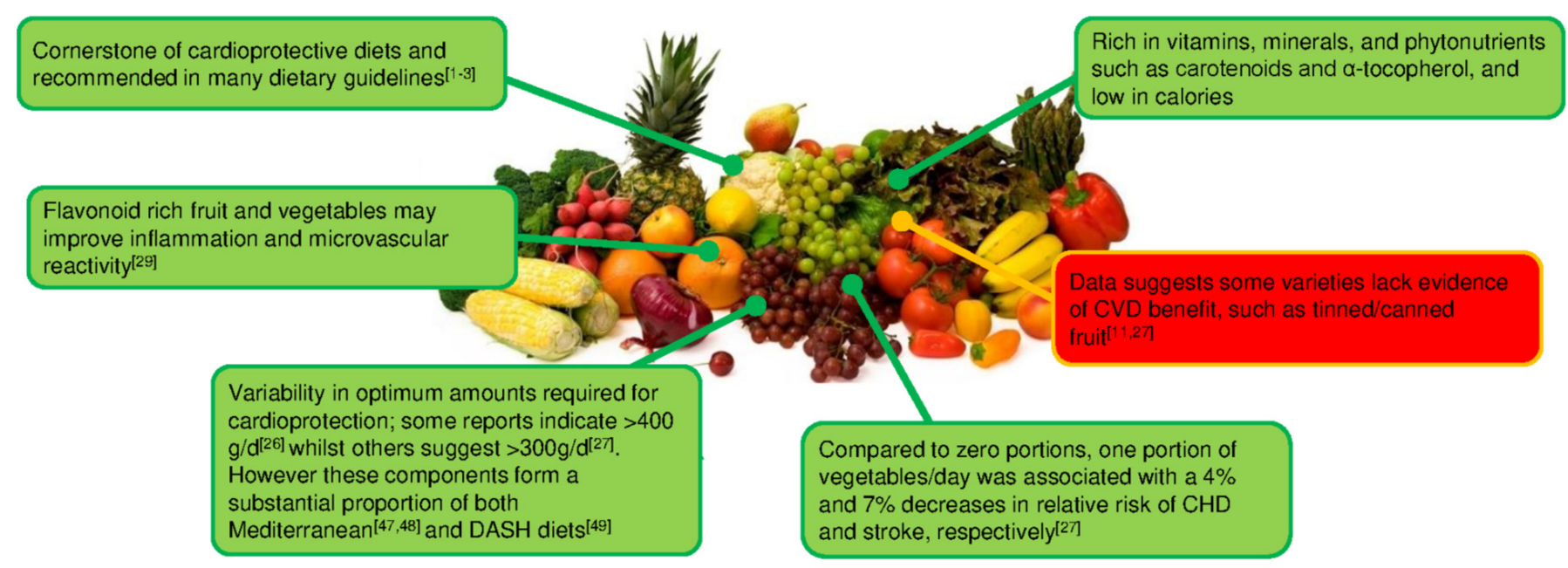

Figure 1 Fruits and vegetables

However, a systematic review and meta-analysis ${ }^{26}$ is notable whereby there was an inverse association between both reported dietary intake and blood concentrations of vitamin C, carotenoids and $\alpha$-tocopherol (markers of fruit and vegetable intake) with risk of CVD, and all-cause mortality. Interestingly, inverse associations between disease/mortality endpoints were stronger for measured biomarkers than for reported dietary intake suggesting that the methodology used to collect this information may be a unreliable. ${ }^{26}$ Multiple studies have shown fruits and vegetables to be consistently associated with reduced CHD and stroke incidence, HTN, and CVD mortality. ${ }^{26}$ However, debate exists on the physical amounts to be consumed, with some suggestions of CHD benefit over $400 \mathrm{~g} / \mathrm{day}^{26}$ and others showing little further benefit of over $300 \mathrm{~g} / \mathrm{day}^{27}$ Existing randomised controlled trials have shown inconsistent effects on established cardiovascular risk markers such as inflammation, blood pressure or lipids, ${ }^{28} 29$ and some varieties appear to lack evidence of CVD benefit altogether. ${ }^{11}{ }^{27}$ Indeed, tinned/canned fruit has been positively associated with all-cause and CVD mortality ${ }^{11} 27$ although the reasons for this observation are not clear and could potentially reflect socioeconomic status. One review only found cardioprotective effects for raw vegetables ${ }^{11}$; however, more varieties were associated with reduced all-cause mortality. It is unclear whether the lack of cardioprotection is true or due to a lack of high-quality research on specific fruits and vegetables (figure 1).

\section{Eggs}

Eggs are a rich source of dietary cholesterol, typically containing $150-230 \mathrm{mg} / \mathrm{egg}$. With the exception of eggs, prawns and liver, most foods rich in cholesterol are also high in saturated fat and it is well established that dietary saturated fat influences levels of circulating low-density lipoprotein-cholesterol (LDL-C) to a much greater extent than dietary cholesterol in foods. ${ }^{30}$ However, the association of egg consumption (and dietary cholesterol) with CVD remains controversial and confusing for patients, particularly those with existing heart disease. The lack of good quality evidence to support the restriction of eggs has resulted in a recent changes to guidelines with many removing any reference to limiting egg and cholesterol intake, ${ }^{13}$ although this is still highlighted in the most recent American guidelines from primary prevention of CVD. ${ }^{2}$

In a very recent analysis of prospective cohort data, Zhong et $a l^{31}$ indicated higher consumption of eggs and dietary cholesterol was positively associated with incident CVD and allcause mortality. These findings are inconsistent with those from previous prospective cohort studies ${ }^{32-35}$ and a large review of meta-analyses ${ }^{11}$ or other prospective studies ${ }^{26}$ showing no association or a benefit to egg consumption However, in Zhong et al, ${ }^{31}$ the effects of egg consumption were modest, and based on selfreported dietary intake at baseline (with an average follow-up of 17 years) in a US population that may not be representative of a UK diet.

In a prospective cohort study of 0.5 million Chinese adults, ${ }^{32}$ a moderate level of egg consumption (up to $<1$ egg per day) was significantly associated with lower risk of CVD. This study demonstrated that each one-egg increment per week was associated with an $8 \%$ lower risk of haemorrhagic stroke. In a subgroup analysis of diabetic populations, greater egg intake was associated with increased rick of CVD and CHD. ${ }^{34}$ The relationship between egg intake and diabetes incidence is not specifically covered here, but the role of egg intake and CVD incidence in people with diabetes requires further consideration made for the overall dietary pattern. However, eggs are a low in calories, high in protein and contain numerous micronutrients. Given their nutrient profile, eggs can form part of a healthy cardioprotective diet (figure 2).

\section{Dairy}

Dairy products have received a great deal of attention in terms of their effect on CVD risk primarily due to their saturated fat content of butter, whole milk and yoghurt, and most cheeses. However, there is increasing evidence that suggests dairy products may actually have a neutral or even a beneficial impact on CVD risk, and that some of the uncertainty in evidence may be related to the different types of dairy. This has been shown by Patterson $e t a l^{36}$ who also highlighted the importance of considering the calcium content of the food. In their analysis, the inverse association between total dairy intake and risk of MI was attenuated by adjustment for calcium with similar observations for cheese and MI risk.

Several recent systematic review and meta-analyses have continued to reinforce the inverse or neutral association between dairy intake and CV health. ${ }^{37-40}$ In a thorough review of systematic reviews and meta-analyses, Fontecha et al ${ }^{40}$ confirmed no association between total dairy intake and CVD. When considering specific subtypes of CVD and dairy, high-fat dairy was not associated with CHD risk, whereas low-fat dairy was associated 


\section{Eggs}

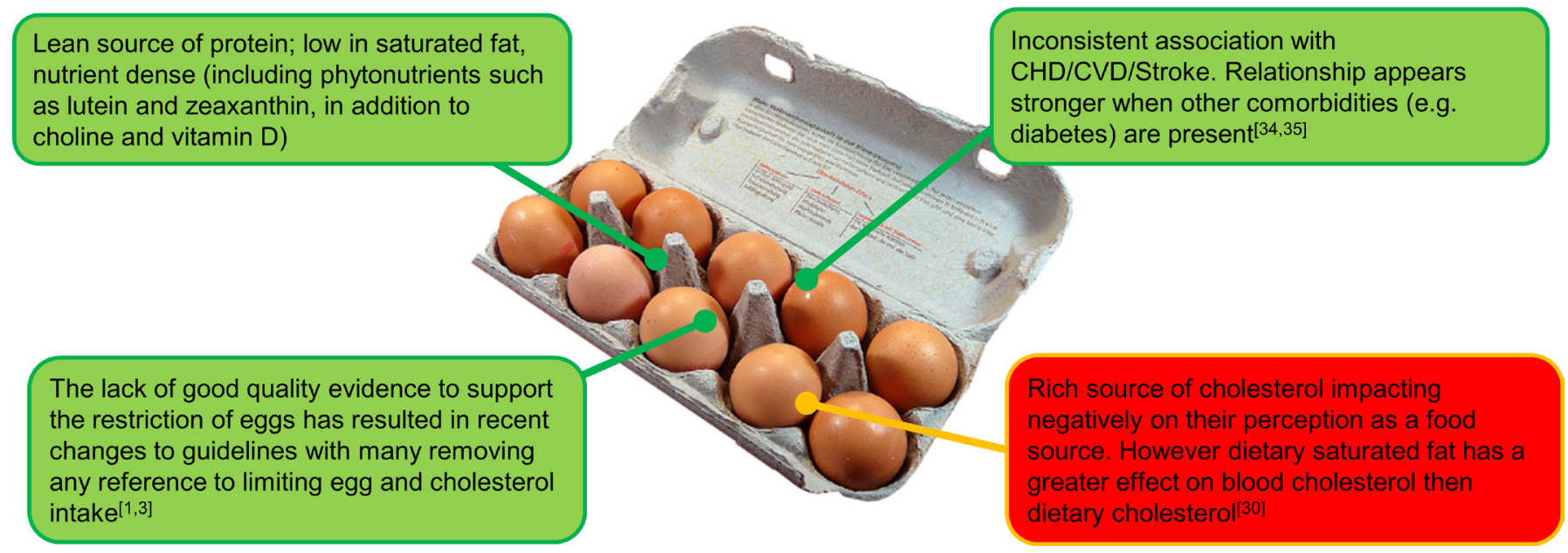

Figure 2 Eggs.

with lower risk. Milk, cheese and yoghurt all appeared to be neutral or inversely associated risk of CHD, stroke or CVD incidence. This paper also considered biomarkers in addition to the hard endpoints of CHD and stroke. Dairy product consumption was not associated with changes in TC or LDL-C. Similar results were also observed for systolic and diastolic blood pressure.

The effects of dairy intake appear to be relatively modest and in some studies, adjusting for total energy intake and consumption of other food groups (such as fruit, vegetables or red meat) can attenuate previously significant associations. Certain dairy products such as cheese are energy dense which could contribute to weight gain if consumed in excess. However, these same foods are high in amino acids known to stimulate muscle growth (leucine) and rich in calcium and phosphorus (figure 3).

\section{Alcohol}

The relationship between alcohol consumption and CVD is still a subject of controversial debate in both primary and secondary prevention. Several meta-analysis have indicated inconsistent relationships between alcohol intake and cardiovascular health. ${ }^{41-45}$ A recent meta-analysis ${ }^{41}$ of 45 studies has shown a significant reduction of CHD mortality for low-volume drinkers and current drinkers comparing to abstainers. In all studies combined, low-volume alcohol consumption was associated with a significantly lower risk of CHD mortality. However, in those studies that excluded participants with heart conditions, low-volume consumption was not associated with reduced CHD mortality. ${ }^{41}$

Drinking patterns are also important to consider in the context of alcohol intake, and compared with moderate drinkers, those individuals who consumed a moderate volume of alcohol but did so more inconsistently had a higher risk of CHD mortality. ${ }^{43}$ This pattern of drinking may partly explain increased risk of an acute MI following a period of higher drinking ${ }^{44}$ and indicates that alcohol use does not have a uniformly protective effect against MI. Patterns of high consumption (perhaps reflecting the social context of alcohol consumption such as binge drinking) must be considered.

A criticism of studies in this area is a lack of acknowledgement that alcohol may have a differential effect on specific types of CVD. Consuming $>100 \mathrm{~g}$ ethanol/week had a higher risk of allcause mortality although a J-shaped relationship existed for all
Source of protein and micronutrients such as calcium. Amino acid profile may be important in stimulating muscle protein synthesis and supporting improvements in function ${ }^{[13]}$
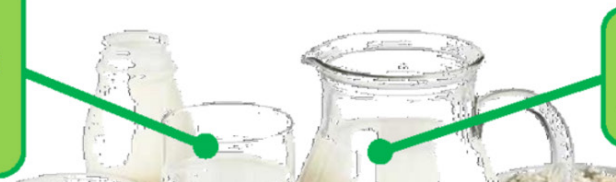

High-fat dairy was not associated with CHD risk, whereas low-fat dairy was associated with lower risk ${ }^{[40]}$
Dairy product consumption was not associated with significant changes in TC and LDL-C, or systolic and diastolic blood pressure ${ }^{[40]}$
Milk, cheese and yoghurt all appeared to be neutral or inversely associated risk of CHD, stroke, or CVD incidence [40]

Figure 3 Dairy. 


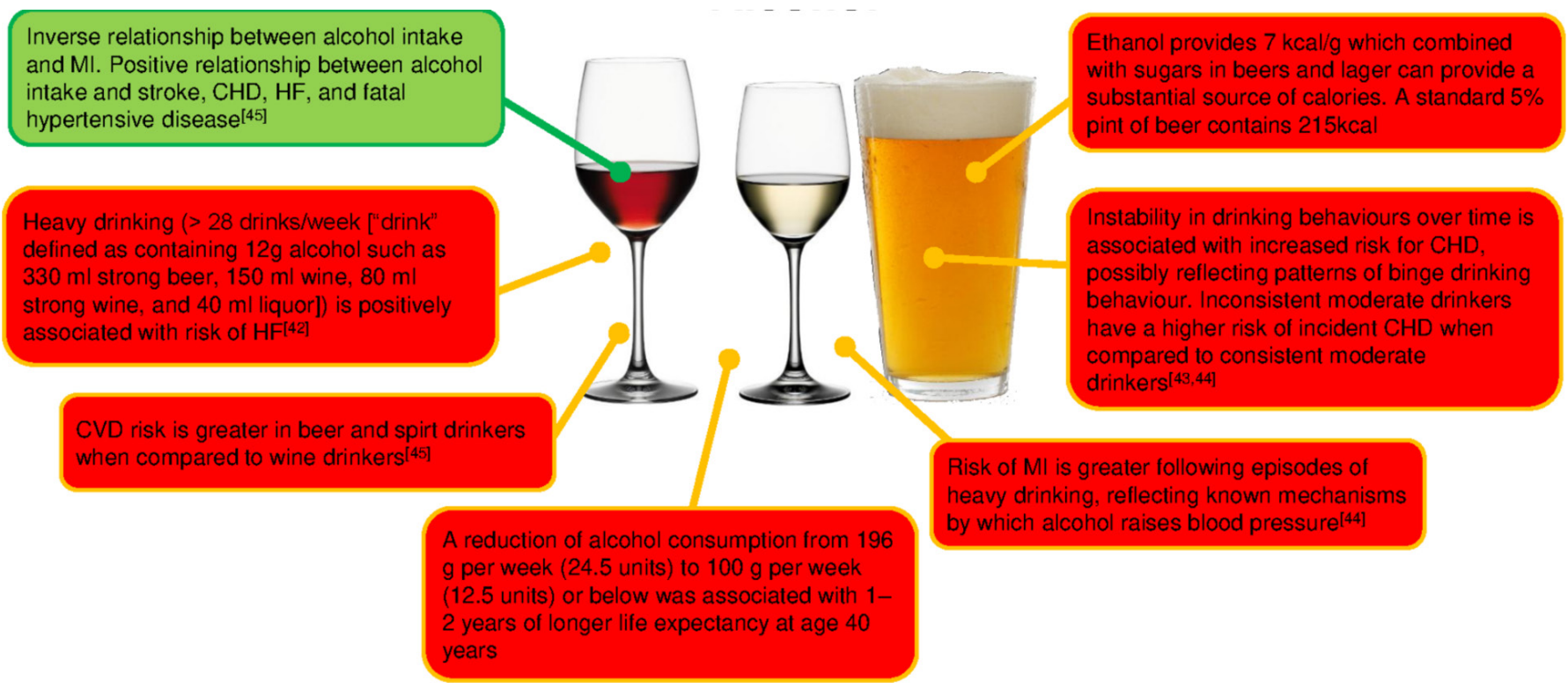

Figure 4 Alcohol.

CVD outcomes. ${ }^{45}$ When this was disaggregated, alcohol intake (per $100 \mathrm{~g} /$ week higher consumption) was positively associated with stroke, CHD, HF and fatal hypertensive disease. With MI as the outcome, there was an inverse log-linear association with alcohol intake. These findings demonstrate how the consistency in frequency and low quantity of alcohol may play an essential role in cardioprotection and prevention. More evidence in needed in those individuals with a previous history of MI (figure 4).

\section{WHOLE DIET APPROACHES}

Studies considering whole diet approaches for CVD prevention are shown in online supplementary table 3.

The previous discussions have highlighted the complexities of nutrition. It is the view of the BACPR diet working group that nutrition research-especially that which impact directly on patients-be focused on food.

Improving diet quality post-MI is associated with a reduction in risk for all-cause mortality, with evidence to suggest it is the whole diet-rather than individual components-that drives this association. ${ }^{46}$ The most widely studied diet pattern in relation to cardiovascular health is the 'Mediterranean' diet (MedDiet), with multiple studies suggesting this diet pattern is associated with lower all-cause mortality in both primary and secondary prevention of CVD. ${ }^{47}$ Broadly speaking, this diet pattern contains a high nutrient density, is rich in fibre, has a relatively high intake of fat (predominantly from olive oil), low intake of saturated fat and a relatively low glycaemic index in comparison to Western diets. Traditionally, it is based around vegetables and fruits, nuts, legumes, and unrefined cereals, moderate fish and shellfish, and fermented dairy products in moderate amounts ${ }^{48}$ but will clearly differ pending on geographical region (eg, Spain vs North Africa). Greater adherence to an 'Alternate MedDiet' characterised by a high intake of vegetables, legumes, fruit, nuts, whole-grain cereals, fish, a high intake of monounsaturated fats, and low consumption of saturated fat, red and processed meats was associated with a pooled relative risk for all-cause mortality of 0.81 in post-MI individuals. ${ }^{47}$ In this same study, a two-point increase in the alternate MedDiet score was associated with a $7 \%$ decrease in all-cause mortality post-MI. This observed level of risk-reduction is also consistent across many other cohort studies examining the association between MedDiet adherence and allcause and CV mortality. ${ }^{48}$ The authors of this study make a clear point that pizza consumed in non-Mediterranean countries should be considered as a type of fast food as it is high in calories, sodium and saturated fat due to the manufacturing process. Similarly, using canola oil (high in polyunsaturated fat) is technically not part of the traditional MedDiet. This means healthcare professionals should be prepared to correct preconceived ideas regarding what is and is not, a MedDiet. Aside from oil type, authorities agree large component of the cardioprotective diet is fruit and vegetables. The established DASH diet (rich in fruits and vegetables, whole grains, low-fat dairy, nuts, legumes, and low in red and processed meat) is associated with decreased incidence of stroke, CVD, CHD, diabetes, in addition to improvements in biomarkers such as systolic and diastolic blood pressure, haemoglobin A1c (HbA1C) and fasting insulin. ${ }^{49}$ The most recent analysis of this topic showed a benefit for greater incorporation of healthy plant foods into the diet, although this benefit was not seen with unhealthy sources (such as refined cereals). Compared with the lowest quintile, those individuals in the highest quintile of a plant-based diet had a lower risk of incident CVD, CVD mortality and all-cause mortality. ${ }^{50}$ Significant reductions in CVD and mortality endpoints were not observed with an unhealthy plant-based diet. Comparing these studies, it can be determined that not all plant-based diets are created equal. More research is needed into plant-based diets and their direct effects post-MI.

A growing area of interest is low-carbohydrate diets and a criticism of the studies cited so far is a lack of consideration of patient subgroups (ie, those with MI vs those with MI + type 2 diabetes mellitus). In this latter group, more aggressive control of carbohydrate intake may be justified and lead to better clinical outcomes. There is a lack of robust clinical evidence for low-carbohydrate diets post-MI and more research is needed in this field. In one recent study, a very low-carbohydrate diet was effective at improving diabetes-related outcomes (HbA1c and diabetes-related drug use) in addition to reducing triglycerides and increasing high-density lipoprotein cholesterol. ${ }^{51}$ The group did exhibit increases in TC and LDL-C which could be argued to 
Table 4 Summary recommendations

\begin{tabular}{|c|c|c|}
\hline Key principles & Examples & Special considerations \\
\hline $\begin{array}{l}\text { Adequate protein is essential to prevent muscle } \\
\text { loss }\end{array}$ & $\begin{array}{l}\text { Good quality animal and plant protein such as lean meat, fish, } \\
\text { dairy and nuts }\end{array}$ & Older people and those with renal disease \\
\hline Include higher fibre carbohydrate foods & $\begin{array}{l}\text { Choose foods high in fibre, for example, wholemeal bread and } \\
\text { pasta instead of refined versions. Include non-starchy vegetables }\end{array}$ & $\begin{array}{l}\text { Portion control and reducing total carbohydrate required to } \\
\text { improve glycaemia }\end{array}$ \\
\hline $\begin{array}{l}\text { Advise reductions in saturated fat on an } \\
\text { individual basis and acknowledge the source }\end{array}$ & $\begin{array}{l}\text { Reducing processed baked pastry goods is more advantageous } \\
\text { than reducing dairy foods for equivalent amount of saturated fat }\end{array}$ & \\
\hline $\begin{array}{l}\text { Consider dairy intake in the context of the overall } \\
\text { diet and health needs }\end{array}$ & As above & \\
\hline $\begin{array}{l}\text { Consume eggs as part of a reduced saturated fat } \\
\text { healthy eating pattern }\end{array}$ & - & $\begin{array}{l}\text { May need to consider amount of egg intake/ } \\
\text { dietary cholesterol intake in individuals with familial } \\
\text { hypercholesterolaemia }\end{array}$ \\
\hline Eat foods naturally rich in unsaturated fats & $\begin{array}{l}\text { Nuts, seeds, oily fish extra virgin olive oil is consumed as part of } \\
\text { the traditional Mediterranean diet }\end{array}$ & - \\
\hline Include plenty of fruit and vegetables & $\begin{array}{l}\text { Root vegetables, green leafy vegetables, for example, kale, } \\
\text { lettuce, spinach; cruciferous vegetables. A variety of fruits should } \\
\text { be included }\end{array}$ & $\begin{array}{l}\text { Ideally fresh or frozen fruit unless canned is the only source } \\
\text { available. Be mindful of total carbohydrate and free sugar } \\
\text { content particularly for those with dysglycaemia }\end{array}$ \\
\hline $\begin{array}{l}\text { For those who drink alcohol to consume within } \\
\text { local government recommendations of no more } \\
\text { than } 14 \text { units/week with } 1-2 \text { alcohol free days } \\
\text { each week. Avoid binge drinking }\end{array}$ & - & - \\
\hline $\begin{array}{l}\text { Use a whole diet approach and tailor approaches } \\
\text { to individual comorbidities and need }\end{array}$ & $\begin{array}{l}\text { A traditional cardioprotective diet rich in vegetables, fruits, nuts, } \\
\text { legumes, unrefined cereals, moderate seafood and fermented } \\
\text { dairy food; low amounts of red and processed meats; olive oil as } \\
\text { main culinary fat }\end{array}$ & $\begin{array}{l}\text { Consider reducing the carbohydrate content particularly for } \\
\text { those with dysglycaemia, and replacing with plant-based } \\
\text { proteins and fats }\end{array}$ \\
\hline
\end{tabular}

be a negative consequence of the diet intervention, especially if extrapolated to a post-MI population. However, this same group showed previously that this increase in LDL-C was accompanied by a decrease in LDL particle number and an increase in LDL particle $\operatorname{size}^{52}$ (suggestive of a more favourable lipid profile). However, it is worth highlighting that there is substantial variation in response to low-carbohydrate diets so monitoring of lipids is important. This study was criticised at the time for patients self-selecting their intervention (not randomised to either treatment or control arm) although this in many ways represents a 'real-world' approach whereby patients are given a choice in their treatment. It is crucial to examine the carbohydrate replacement element and its source (fat vs protein, and animal or plant sources) as this will also govern the impact this diet pattern has on CV health. Indeed, a recent meta-analysis has indicated a plant-based low-carbohydrate diet is inversely associated with lower risk of mortality whereas an animal-based low-carbohydrate diet was positively associated with the same outcome. ${ }^{15}$ This highlights the importance for healthcare practitioners to explore diet choices with their patients, and not automatically assume plant-based or low-carbohydrate diets are 'good' and 'bad', respectively.

\section{CONCLUSION}

Recommendations from the working group are summarised in table 4. Focusing on macronutrients can be problematic with advice such as 'reduce saturated fat' and increase monounsaturated and polyunsaturated fats being vague and non-specific. The greatest improvement in cardiovascular outcomes will be seen when patients are provided with food-based advice. This requires those dispensing this information to have an understanding of nutritional science and an appreciation for the patients' comorbidities. While there is a large body of evidence for the role of the MedDiet, additional approaches should be used in the right groups of patients. Low-carbohydrate diets can be carefully planned and be very nutritious, although similar to plant-based diets they can also be poor quality if not planned appropriately. Nutritional advice needs to be patient-focused, flexible, and should be adapted to each individual with CVD and their other comorbidities. More specialised dietitians are required in this area to guide the multi-professional team and provide guidance and training to those involved in the individual's rehabilitation journey.

\section{Twitter Tom Butler @drtom_butler and Conor P Kerley @@conorkerley}

Acknowledgements The authors acknowledge their colleagues for their comments and feedback on the manuscript.

Contributors All authors contributed equally to the searches, design and writing of the manuscript.

Funding This publication was supported by the British Association for Cardiovascular Prevention and Rehabilitation (BACPR)

Competing interests None declared.

Patient consent for publication Not required.

Provenance and peer review Commissioned; externally peer reviewed.

Open access This is an open access article distributed in accordance with the Creative Commons Attribution Non Commercial (CC BY-NC 4.0) license, which permits others to distribute, remix, adapt, build upon this work non-commercially, and license their derivative works on different terms, provided the original work is properly cited, appropriate credit is given, any changes made indicated, and the use is non-commercial. See: http://creativecommons.org/licenses/by-nc/4.0/.

\section{ORCID iD}

Tom Butler http://orcid.org/0000-0003-0818-1566

\section{REFERENCES}

1 Piepoli MF, Hoes AW, Agewall S, et al. European Guidelines on cardiovascular disease prevention in clinical practice: The Sixth Joint Task Force of the European Society of Cardiology and Other Societies on Cardiovascular Disease Prevention in Clinical Practice (constituted by representatives of 10 societies and by invited experts) Developed with the special contribution of the European Association for Cardiovascular Prevention \& Rehabilitation (EACPR). Eur Heart J 2016;2016:2315-81.

2 Arnett DK, Blumenthal RS, Albert MA, et al. ACC/AHA guideline on the primary prevention of cardiovascular disease: a report of the American College of Cardiology/ American heart association Task force on clinical practice guidelines. Circulation 2019;2019:e596-646. 
3 JBS3 Board. Joint British societies' consensus recommendations for the prevention of cardiovascular disease (JBS3). Heart 2014;100:ii1-67.

4 Graudal N, Hubeck-Graudal T, Jürgens G, et al. Dose-Response relation between dietary sodium and blood pressure: a meta-regression analysis of 133 randomized controlled trials. Am J Clin Nutr 2019;109:1273-8.

5 Graudal N, Jürgens G, Baslund B, et al. Compared with usual sodium intake, low- and Excessive-Sodium diets are associated with increased mortality: a meta-analysis. Am J Hypertens 2014;27:1129-37.

6 BHF. The National audit of cardiac rehabilitation: quality and outcomes report 2018, 2018. Available: https://www.bhf.org.uk/informationsupport/publications/statistics/ national-audit-of-cardiac-rehabilitation-quality-and-outcomes-report-2018

7 Esmeijer K, Geleijnse JM, de Fijter JW, et al. Dietary protein intake and kidney function decline after myocardial infarction: the alpha omega cohort. Nephrol Dial Transplant 2019:365.

8 Virtanen HEK, Voutilainen S, Koskinen TT, et al. Dietary proteins and protein sources and risk of death: the Kuopio ischaemic heart disease risk factor study. Am J Clin Nutr 2019;109:1462-71.

9 O'Connor LE, Paddon-Jones D, Wright AJ, et al. A Mediterranean-style eating pattern with lean, unprocessed red meat has cardiometabolic benefits for adults who are overweight or obese in a randomized, crossover, controlled feeding trial. Am J Clin Nutr 2018;108:33-40.

10 Guasch-Ferré M, Satija A, Blondin SA, et al. Meta-Analysis of randomized controlled trials of red meat consumption in comparison with various comparison diets on cardiovascular risk factors. Circulation 2019;139:1828-45.

11 Kwok CS, Gulati M, Michos ED, et al. Dietary components and risk of cardiovascular disease and all-cause mortality: a review of evidence from meta-analyses. Eur J Prev Cardiol 2019;26:1415-29.

12 Franzke B, Neubauer O, Cameron-Smith D, et al. Dietary protein, muscle and physical function in the very old. Nutrients 2018;10:935

13 Park Y, Choi J-E, Hwang H-S. Protein supplementation improves muscle mass and physical performance in undernourished prefrail and frail elderly subjects: a randomized, double-blind, placebo-controlled trial. Am J Clin Nutr 2018:108:1026-33.

14 Dehghan M, Mente A, Zhang X, et al. Associations of fats and carbohydrate intake with cardiovascular disease and mortality in 18 countries from five continents (pure): a prospective cohort study. The Lancet 2017;390:2050-62.

15 Seidelmann SB, Claggett B, Cheng S, et al. Dietary carbohydrate intake and mortality: a prospective cohort study and meta-analysis. The Lancet Public Health 2018;3:e419-28.

16 Li S, Flint A, Pai JK, et al. Low carbohydrate diet from plant or animal sources and mortality among myocardial infarction survivors. J Am Heart Assoc 2014;3:e001169.

17 Li S, Flint A, Pai JK, et al. Dietary fiber intake and mortality among survivors of myocardial infarction: prospective cohort study. BMJ 2014;348:92659.

18 Zhang B, Zhao Q, Guo W, et al. Association of whole grain intake with all-cause, cardiovascular, and cancer mortality: a systematic review and dose-response metaanalysis from prospective cohort studies. Eur J Clin Nutr 2018;72:57-65.

19 Kelly SA, Hartley L, Loveman E, et al. Whole grain cereals for the primary or secondary prevention of cardiovascular disease. Cochrane Database Syst Rev 2017:8:CD005051

20 Hooper L, Martin N, Abdelhamid A, et al. Reduction in saturated fat intake for cardiovascular disease. Cochrane Database Syst Rev 2015:CD011737.

21 Zhuang P, Zhang Y, He W, et al. Dietary Fats in Relation to Total and Cause-Specific Mortality in a Prospective Cohort of 521120 Individuals With 16 Years of Follow-Up. Circ Res 2019:124:757-68.

22 Hooper L, Al-Khudairy L, Abdelhamid AS, et al. Omega-6 fats for the primary and secondary prevention of cardiovascular disease. Cochrane Database Syst Rev 2018;11:CD011094

23 Aung T, Halsey J, Kromhout D, et al. Associations of Omega-3 Fatty Acid Supplement Use With Cardiovascular Disease Risks: Meta-analysis of 10 Trials Involving 77917 Individuals. JAMA Cardiol 2018;3:225-33.

24 Bhatt DL, Steg PG, Miller M, et al. Effects of Icosapent Ethyl on Total Ischemic Events. J Am Coll Cardiol 2019;73:2791-802.

25 Yip CSC, Chan W, Fielding R. The associations of fruit and vegetable intakes with burden of diseases: a systematic review of meta-analyses. J Acad Nutr Diet 2019:119:464-81.

26 Aune D, Keum N, Giovannucci E, et al. Dietary intake and blood concentrations of antioxidants and the risk of cardiovascular disease, total cancer, and all-cause mortality: a systematic review and dose-response meta-analysis of prospective studies. Am J Clin Nutr 2018:108:1069-91.

27 Bechthold A, Boeing H, Schwedhelm C, et al. Food groups and risk of coronary heart disease, stroke and heart failure: a systematic review and dose-response metaanalysis of prospective studies. Crit Rev Food Sci Nutr 2019;59:1071-90.
28 Macready AL, George TW, Chong MF, et al. Flavonoid-Rich fruit and vegetables improve microvascular reactivity and inflammatory status in men at risk of cardiovascular disease-FLAVURS: a randomized controlled trial. Am J Clin Nutr 2014:99:479-89.

29 McEvoy CT, Wallace IR, Hamill LL, et al. Increasing fruit and vegetable intake has no dose-response effect on conventional cardiovascular risk factors in overweight adults at high risk of developing cardiovascular disease. J Nutr 2015;145:1464-71.

30 Soliman G. Dietary cholesterol and the lack of evidence in cardiovascular disease. Nutrients 2018;10:780.

31 Zhong VW, Van Horn L, Cornelis MC, et al. Associations of dietary cholesterol or egg consumption with incident cardiovascular disease and mortality. JAMA 2019;321:1081-95.

32 Qin C, Lv J, Guo Y, et al. Associations of egg consumption with cardiovascular disease in a cohort study of 0.5 million Chinese adults. Heart 2018;104:1756-63.

33 Alexander DD, Miller PE, Vargas AJ, et al. Meta-Analysis of egg consumption and risk of coronary heart disease and stroke. J Am Coll Nutr 2016;35:704-16.

34 Rong Y, Chen L, Zhu T, et al. Egg consumption and risk of coronary heart disease and stroke: dose-response meta-analysis of prospective cohort studies. BMJ 2013:346:e8539.

35 Shin JY, Xun P, Nakamura Y, et al. Egg consumption in relation to risk of cardiovascular disease and diabetes: a systematic review and meta-analysis. Am J Clin Nutr 2013;98:146-59.

36 Patterson E, Larsson SC, Wolk A, et al. Association between dairy food consumption and risk of myocardial infarction in women differs by type of dairy food. J Nutr 2013;143:74-9.

37 Alexander DD, Bylsma LC, Vargas AJ, et al. Dairy consumption and CVD: a systematic review and meta-analysis. Br J Nutr 2016;115:737-50.

38 Soedamah-Muthu SS, de Goede J, Consumption D. Dairy consumption and cardiometabolic diseases: systematic review and updated meta-analyses of prospective cohort studies. Curr Nutr Rep 2018;7:171-82.

39 Buziau AM, Soedamah-Muthu SS, Geleijnse JM, et al. Total fermented dairy food intake is inversely associated with cardiovascular disease risk in women. J Nutr 2019:149:1797-804.

40 Fontecha J, Calvo MV, Juarez M, et al. Milk and dairy product consumption and cardiovascular diseases: an overview of systematic reviews and meta-analyses. Adv Nutr 2019;10:5164-89.

41 Zhao J, Stockwell T, Roemer A, et al. Alcohol consumption and mortality from coronary heart disease: an updated meta-analysis of cohort studies. J Stud Alcohol Drugs 2017:78:375-86

42 Larsson SC, Wallin A, Wolk A. Contrasting association between alcohol consumption and risk of myocardial infarction and heart failure: two prospective cohorts. Int J Cardiol 2017;231:207-10

43 O'Neill D, Britton A, Hannah MK, et al. Association of longitudinal alcohol consumption trajectories with coronary heart disease: a meta-analysis of six cohort studies using individual participant data. BMC Med 2018;16:124.

44 Leong DP, Smyth A, Teo KK, et al. Patterns of alcohol consumption and myocardial infarction risk. Circulation 2014;130:390-8.

45 Wood AM, Kaptoge S, Butterworth AS, et al. Risk thresholds for alcohol consumption: combined analysis of individual-participant data for 599912 current drinkers in 83 prospective studies. The Lancet 2018;391:1513-23.

46 Li S, Chiuve SE, Flint A, et al. Better diet quality and decreased mortality among myocardial infarction survivors. JAMA Intern Med 2013;173:1808-18.

47 Lopez-Garcia E, Rodriguez-Artalejo F, Li TY, et al. The Mediterranean-style dietary pattern and mortality among men and women with cardiovascular disease. Am J Clin Nutr 2014:99:172-80.

48 Martínez-González Miguel Ángel, Hershey MS, Zazpe I, et al. Transferability of the Mediterranean diet to Non-Mediterranean countries. What is and what is not the Mediterranean diet. Nutrients 2017;9:E1226.

49 Chiavaroli L, Viguiliouk E, Nishi SK, et al. Dash dietary pattern and cardiometabolic outcomes: an umbrella review of systematic reviews and meta-analyses. Nutrients 2019;11:338.

$50 \mathrm{Kim} \mathrm{H}$, Caulfield LE, Garcia-Larsen V, et al. Plant-Based diets are associated with a lower risk of incident cardiovascular disease, cardiovascular disease mortality, and All-Cause mortality in a general population of Middle-Aged adults. J Am Heart Assoc 2019;8:e012865

51 Athinarayanan SJ, Adams RN, Hallberg SJ, et al. Long-Term effects of a novel continuous remote care intervention including nutritional ketosis for the management of type 2 diabetes: a 2-year Non-randomized clinical trial. Front Endocrinol 2019;10:348.

52 Bhanpuri NH, Hallberg SJ, Williams PT, et al. Cardiovascular disease risk factor responses to a type 2 diabetes care model including nutritional ketosis induced by sustained carbohydrate restriction at 1 year: an open label, non-randomized controlled study. Cardiovasc Diabetol 2018;17:56. 